\title{
TRANSTORNO E COMPORAMENTO ALIMENTAR NOS UNIVERSITÁRIOS DA ÁREA DA SAÚDE
}

\author{
Gilvane Amarante ${ }^{1}$; Débora Millani ${ }^{2}$; Franceliane Jobim Benedetti ${ }^{3}$
}

\section{RESUMO}

Esse estudo tem o intuito de fazer uma revisão narrativa da literatura de artigos científicos sobre transtorno e comportamento alimentar de estudantes da área da saúde. Na atualidade, os estudantes e profissionais da saúde - inclusive os de Nutrição - não são imunes ao desenvolvimento de inadequações profundas no consumo, padrão e comportamento alimentar. Portanto, este estudo tem por objetivo investigar na literatura científica os transtornos e comportamentos de universitários na área da saúde. Os resultados contataram que a relação entre o ambiente familiar conflituoso, universitário de carga horária extensa e das redes sociais influenciando negativamente nas manifestações de transtornos alimentares nos cursos da área da ciência da saúde, em razão da pressão dos padrões estéticos. Conclui-se que muitos universitários da área da saúde, principalmente do sexo feminino, apresentam algum grau de insatisfação com a sua imagem corporal; prevalência de comportamentos alimentares inadequados e atitudes indicativas de transtornos alimentares.

Palavras-chave: Estudantes de Ciências da Saúde; Imagem Corporal; Transtornos da Alimentação e da Ingestão de Alimentos; Universidades.

Eixo Temático: Atenção Integral e Promoção à Saúde - AIPS.

\section{INTRODUÇÃO}

Os transtornos alimentares (TAs) são doenças de quadros psicopatológicos, onde se caracterizam por modificações nos hábitos e comportamento alimentar. Além disso, estudantes do ensino superior podem vir a desenvolver TAs, por consequência na mudança de rotina, por pressões psicológicas e falta de tempo para alimentar-se adequadamente, tendo que optar, muitas vezes, por lanche rápidos e pouco nutritivos. Desse modo, alguns estudantes acabam por desencadear anorexia nervosa, em que manifestam uma imagem corporal distorcida, medo de engordar, rejeição de se

\footnotetext{
${ }^{1}$ Gilvane Maciel do Amarante - Curso de Nutrição, Universidade Franciscana (UFN) gilvane.amarante@gmail.com

${ }^{2}$ Débora Millani - Curso de Nutrição, Universidade Franciscana (UFN) - deboramillani2@gmail.com

${ }^{3}$ Franceliane Jobim Benedetti - Professora orientadora, Curso de Nutrição, Universidade Franciscana (UFN) - franceliane@ufn.edu.br
} 
alimentar, preocupação excessiva com a alimentação e ganho de peso (MOREIRA et al., 2017).

Além de que, existem diversos fatores que podem influenciar essa doença, onde a mídia e a sociedade têm um papel fundamental, pois todos querem corresponder à imagem que são expostos. Da mesma forma, eles são pressionados de diversas formas: seja pelo fabricante de roupas, pela publicidade alimentar com os produtos "milagrosos", ou pela propaganda e comerciais passados na televisão, pela valorização de uma determinada imagem. Assim, neste contexto os profissionais ou estudantes da área da saúde, principalmente os do sexo feminino, são uns dos grupos mais vulneráveis a esses riscos, uma vez que, eles têm uma visão distorcida sobre a "boa aparência" por serem de um curso da área da saúde ou estarem cursando o mesmo (SOUZA et al., 2020).

Já é sabido que a vaidade é uma grande característica do povo brasileiro, e que devido a isso a cobrança por profissionais dessas áreas estarem adequados ao padrão imposto pela sociedade é diretamente relacionada a capacidade ou não de serem bons profissionais, portanto este estudo tem por objetivo investigar na literatura científica os transtornos e comportamentos de universitários na área da saúde.

\section{METODOLOGIA}

Trata-se de uma revisão narrativa da literatura, no qual foram utilizados para busca de artigos os descritores: Transtorno da Alimentação e da Ingestão de Alimentos, Estudantes de Ciência da Saúde, Comportamento Alimentar, Universidades para a busca dos documentos. Além disso, a busca foi realizada, segundo estratégia predefinida, resultando em um achado de 3,780 artigos, referenciados no Google Acadêmico, publicados entre os anos de 2017 e 2021. Deste total de estudos, foram selecionados 6 trabalhos sobre transtorno e comportamento alimentar nos universitários da área da saúde.

\section{RESULTADOS E DISCUSSÕES}


Segundo Lizot e Nicoletto (2019), em um estudo com 130 alunos do curso de nutrição, onde foram avaliados 118 alunos do sexo feminino e 12 do sexo masculino com um intervalo de idade entre 20 e 26 anos. Deste modo, foi realizado uma pesquisa, no qual foi diagnosticado que $59,2 \%$ dos acadêmicos, é insatisfeito com a sua imagem corporal de acordo com a escala de silhuetas corporais. Além disso, $12,3 \%$ apresentam uma prevalência de preocupação com a imagem corporal, segundo BSQ (Body Shape Questionnarire), e 16,2\% conforme o EAT (Eating Attitudes Test), apresentam uma prevalência de comportamentos alimentares inadequados.

Ainda, uma pesquisa onde foram avaliados 399 alunos, maior parte do sexo feminino entre 20 e 24 anos, com renda familiar de 2 até 10 salários, onde os indivíduos que participaram deste estudo foram constituídos por graduandos dos cursos da área da saúde, quais sejam: Biomedicina, Educação Física, Enfermagem, Fisioterapia, Medicina, Nutrição e Terapia Ocupacional, porém o curso que teve maior participação foi o curso de medicina (29,6\%). Uma vez que, foi constatado que, o curso de nutrição, apresentou atitudes alimentares mais inadequadas comparada, com os outros cursos da área da saúde. Além tudo, mostrou que, quanto maior a idade, o período acadêmico e quanto menor for a renda familiar, mais inadequado é comportamento alimentar e maior risco de desenvolvimento de transtorno alimentar (COSTA et al., 2018).

Salienta-se, que uma pesquisa feita na universidade de Santa Cruz do Sul, com 225 alunas matriculadas em 8 curso da área da saúde, revelou que 69,8\% estavam com eutrofia, porém $74,7 \%$ delas gostariam de pesar menos, onde $64,9 \%$ dessas eram eutróficas. Inclusive, conforme o Body Shape Questionnaire (BSQ) 51,1\% das universitárias tiveram algum grau de insatisfação corporal, e a prevalência de atitudes indicativas de transtornos alimentares, de acordo com o Eating Attitudes Test (EAT$26)$, foi de $21,8 \%$, no qual ao relacionar as atitudes de risco para transtornos alimentares e a insatisfação da imagem corporal, constatou que $87,75 \%$ das alunas manifestam algum grau de insatisfação corporal. Por conseguinte, apresentou uma correlação entre a insatisfação com a imagem corporal e atitudes de risco para transtornos alimentares e estado nutricional (KESSLER; POLL, 2018). 
Os estudos demonstraram uma média de 21,4 anos e IMC de 22,75 kg/m² entre os estudantes da área da saúde, já as médias do curso da Nutrição foram menores, correspondendo a 21,55 kg/m². Foi observado que a maioria dos alunos deseja perder peso e sente-se incomodado com o peso atual, apesar do curso de medicina corresponder as menores médias de risco de transtorno alimentar (SAMPAIO et al., 2019).

Os resultados de TA são ainda mais elevados quando tratados nos cursos de Educação Física e Nutrição, pelo fato de associarmos a estética corporal com a competência profissional, podendo ser ainda mais significativo em alunos da nutrição, em que $14,1 \%$ dos alunos da nutrição e 10,3\% do curso de educação física positivou (SAMPAIO et al., 2019).

Os alunos da área da saúde estão mais propensos a possuir TA que alunos de outros cursos, correspondendo a 50\% em Nutrição, 24\% em Educação Física, 13\% em Publicidade e Propaganda e 18\% em Administração de Empresas. Os estudantes da área da saúde com famílias conflituosas são mais propensos a possuírem transtornos alimentares, pois não possuem amparo emocional para situações conflituosas (SAMPAIO et al., 2019).

O estudo realizado com os alunos da medicina, educação física, psicologia e enfermagem, com idades variando de 17 a 21 anos, através do estudo da Escala de Satisfação com a Imagem Corporal (ESIC) foi obtido média de 66,23, no qual o curso com maior satisfação corporal e menor preocupação com o peso foi da educação física, apesar da pressão estética. Enquanto, o curso de enfermagem resultou em maior percentual de risco para desenvolver a patologia, ainda foram obtidos dados que $52,25 \%$ e $79,97 \%$ desejam mudar a aparência ou que ela fosse melhor respectivamente (PINTO; QUADRADO, 2018).

Quando nos referimos a insatisfação corporal $(m=46,86 ; d p=8,17)$ e preocupação com peso $(m=17,28 ; d p=4,08)$ em mulheres é mais frequente em razão da pressão social ao corpo magro quando comparado a homens ( $m=49,33 ; \mathrm{dp}=8,23$ e $m=20,33 ; d p=3,99$ ). No teste do EAT-26 obteve-se os seguintes dados, $18,9 \%$ possuem risco de transtorno alimentar, combinado ao ESIC foi analisado que quanto 
maior a insatisfação corporal, maior o risco de desenvolver TA (PINTO; QUADRADO, 2018).

O estudo realizado com as estudantes do $2^{\circ}$ ao $8^{\circ}$ semestre do curso de medicina da Unicamp, demonstrou média de 76,62\% com o IMC adequado, 3,25\% abaixo do peso e 14,29\% acima do peso, apesar da maioria das estudantes possuírem IMC adequado, o estudo do EAT-26 manifesta que $30,5 \%$ das alunas possuem imagem negativa em relação ao corpo, com $19 \%$ dos alunos com risco para TA, percebe-se o aumento significativo dos casos comparado com a média nacional para transtornos alimentares variando de $23,7 \%$ a $30,1 \%$, resultante de números maiores que o esperado (LOPES et al., 2020).

Ao associarmos o EAT-26 ao IMC percebe-se que as alunas que estão abaixo do peso não demonstram risco para desenvolver transtorno alimentar, enquanto $29,66 \%$ que possui IMC adequado e 38,7\% acima do peso possuem risco, em contrapartida a associação do EAT-26 e BSQ comprova a insatisfação corporal associada ao comportamento alimentar inadequado, resultando na busca pelo corpo ideal. Além dos padrões estéticos as mulheres quando submetidas a situações de estresse estão mais propensas a comer por impulsividade (LOPES et al., 2020).

A mudança de rotina é outro fator para desenvolver transtorno alimentar, em razão de possuir horários diferentes e menor tempo para exercer hábitos saudáveis, resultando em ganho de peso e práticas alimentares inadequados, consequentemente em menor satisfação corporal e de autoestima, ao associarmos o transtorno de humor (TH) ao TCA encontra-se maiores casos de bulimia e anorexia (LOPES et al., 2020).

\section{CONCLUSÃO}

O presente estudo relatou a relação entre o ambiente familiar conflituoso, universitário de carga horária extensa e das redes sociais influenciando negativamente nas manifestações de transtornos alimentares nos cursos da área da ciência da saúde, em razão da pressão dos padrões estéticos. Além da importância de desenvolver projetos para minimizar a ocorrência de TA e insatisfação corporal nos alunos, quanto nas pessoas atendidas, orientando-os de modo consciente, ressalta- 
EDUCAÇ̃̃O, SAÚDE

ETECNOLOGIA

26 A 28 DE OUTUBRO DE 2021

se ainda a relevância da alimentação adequados nas situações econômicas de cada grupo.

\section{REFERÊNCIAS}

COSTA, D.G. et al. Qualidade de vida e atitudes alimentares de graduandos da área da saúde. REBEn- Revista Brasileira de Enfermagem, 71 (suppl 4), 2018. Disponível em: https://doi.org/10.1590/0034-7167-2017-0224. Acesso em: 21 jun. 2021.

KESSLER, A.M; POLL, F.A. Relação entre imagem corporal, atitudes para transtornos alimentares e estado nutricional em universitárias da área da saúde. Jornal Brasileiro de Psiquiatria, v.67, n.2, p.118-125, 2018. Disponível em: https://doi.org/10.1590/0047-2085000000194. Acesso em: 22 jun. 2021.

LIZOT, L. A. B.; NICOLETTO, B. B. Comportamento alimentar e imagem corporal em acadêmicos de Nutrição de uma Universidade privada da Serra Gaúcha. RBONE Revista Brasileira de Obesidade, Nutrição e Emagrecimento, v. 12, n. 76, p. 1141-1149, 27 jan. 2019.

LOPES, I.P et al, Comportamento alimentar entre estudantes de medicina de uma Universidade privada em Campo Grande - Mato Grosso do Sul. Jornal brasileiro de desenvolvimento. v. 6, n. 10. Disponível em:

https://www.brazilianjournals.com/index.php/BRJD/article/view/17733. Acesso em: 29 jun 2021.

MOREIRA, D. E. et al. Transtornos alimentares, percepção da imagem corporal e estado nutricional: estudo comparativo entre estudantes de Nutrição e Administração. Revista da Associação Brasileira de Nutrição - RASBRAN, [S. I.], v. 8, n. 1, p. 18-25, 2017. Disponível em:

https://www.rasbran.com.br/rasbran/article/view/232. Acesso em: 20 jun. 2021. 


\section{QUFN}

PINTO, D. C. D.; QUADRADO, R. P. Imagens em construção: satisfação corporal e transtornos alimentares em acadêmicos da área da saúde. RELACult - Revista Latino-Americana de Estudos em Cultura e Sociedade, [S. I.], v. 4, 2018. DOI: 10.23899/relacult.v4i0.759. Disponível em:

https://periodicos.claec.org/index.php/relacult/article/view/759. Acesso em: 29 jun. 2021.

SAMPAIO, H.A.C. et al. Ambiente familiar e risco de transtorno alimentar entre universitários da área de saúde. Revista DEMETRA alimentação, nutrição \& saúde. v. 14, 2019. Disponível em: https://www.e-

publicacoes.uerj.br/index.php/demetra/article/view/33308. Acesso em: 29 jun 2021.

SOUZA, F. et al. Estudo do estado nutricional, imagem corporal e atitudes para transtornos alimentares em acadêmicos de nutrição. Revista Enfermagem Atual, v. 93 n. 31, 2020. Disponível em:

https://revistaenfermagematual.com.br/index.php/revista/article/view/644 . Acesso em: 20 jun. 2021. 